\title{
Drug Abuse, Addiction and Dependence
}

\author{
Alewu Benjamin and Nosiri Chidi \\ Additional information is available at the end of the chapter \\ http://dx.doi.org/10.5772/58574
}

\section{Introduction}

Before the dawn of civilization, they are natural substances that were discovered e.g euphoria's, narcotics, hallucinogens, excitants. Some of these were used by farmers. In fact, there were dope addict long before they were farmers. There are certain drives that persuade or compel somebody to resort to drug to obtain vacation from intolerable selfhood. One of the principal appetite of the soul is the urge to escape if for a few seconds the painful aspect of life, acquisition of wealth which may not be forthcoming. The distinguishing facts between legitimate use of drug for social purpose and their abuse are not certain if not indistinct. It is not a matter of which drug but the amount taken and if directed anti-socially or not. For instance normal people use alcohol for their occasional purpose without harm but, here there is appropriate degree of mental abnormality to the individual and the society as well. These people may then depend on it physically or emotionally [1]

Drug abuse is not a pharmacological problem but a social problem with pharmacological aspect. In connection with the use of drugs, such terms as 'abuse' 'misuse', 'addiction', 'habitforming', 'tolerance' and 'dependence', which are often used interchangeably, should be properly defined [2] officially adopted the following usages:

Abuse: Drug use without medical supervision.

Misuse: Wrong use of drug under medical supervision.

Addiction: Specific side or adverse effect of drugs caused by prolonged use. In the case of addiction WHO recommend the use of the term dependence, subdivided into psychological or physical. Further, such terms as 'habit-forming' and 'tolerance' should also be properly defined in advance of dealing with problems of drug use. 
Drug abuse is defined as 'the drug use that is not generally accepted on medical ground. In other words it is non-prescribed or social drug use. This means a continuous or occasional use of drug by the individual either of his own choice or under feeling of compulsion, to achieve his own well being or what he conceives as his own well being". Drug addiction on the other hand is to devote or apply habitually these simple medicinal organic or inorganic ingredients in medicine. There is much-belated attempt by the scientific community to sever its conceptual apparatus from the vocabulary of politics and emotion. "Addiction," like "narcotics" and "drug abuse," has a general connotation of evil, suggesting illicit ecstasy, guilt and sin because the public image is conditioned more by cultural perceptions than by medical ones. Medicallyprecise meanings simply cannot be harmonized with common parlance." This may have come because of ambiguity in meaning as in relating drug abuse to a cluster of symptoms previously called "Substance Abuse" [3]

Drug abuse needs some clarifications and that the term is really convenient, but not very precise way of indicating that an unspecified drug is being used in an unspecified manner and amount ... and such use has been judged by some person or group to be wrong (illegal or immoral) and/or harmful to the user or society, or both. What might be called "drug abuse" by some would not necessarily be considered so by others. ... For these reasons, the term "drug abuse" is avoided here" [4] in Wikipedia). It has come to fore why World Health Organization presently prefers to use the terms "harmful use" and "hazardous use" of drugs. This may be to distinguish between the health's effects of drug abuse rather than the social consequences. According to [2], the term "Misuse" may be less judgmental hence preferred

Poly drug abuse is used to refer to:

a. Simultaneous or sequential non-medical use of more than one psychoactive drug [14]

b. The abuse of any psychoactive drug singly, in combination or sequentially which does not include heroin or alcohol as the primary drug. This was defined by the Federal Government in USA. One that is associated with therapeutic settings. Therefore, clinicians have a responsibility to avoid prescribing potentially habituating drugs for longer periods than is absolutely necessary, especially in the case of individuals who are known to abuse any agent e.g chronic alcoholics.

In drug abuse, the drug is obtained illicitly and the prescribed drugs are used in dosages beyond that prescribed medically. Over the counter drugs used is beyond the amount recommended on the package. Drug abuse is associated with urban crime. Most heroine abuse also abuse a variety of psychoactive substances, either in combination or in succession.

Drug abuse is a complicated phenomenon which is related to inter personal need, psychic and physical problems, and social adaptation. No one substance could be targeted as "brand switching" commonly occurred among individuals. The choice of a particular drug abuse and addiction appeared to be dictated primarily by availability. Differences in the pattern of abuse between geographic areas and among different population became apparent. 
Drug addiction is a chronic, often brain disease that causes compulsive drug seeking and use, despite harmful consequences to the addicted individual and to those around him or her. Although the initial decision to take drugs is voluntary for most people, the brain changes that occur over time challenges an addicted person's self control and hamper his or her ability to resist intense impulses to take drugs [5]

\subsection{Scope of the problem}

The abuse of drugs has reached an epidemic proportion during the 1960's and early 1980's. The actual number of drug abusers is difficult to ascertain because of illegality of its use and some of the drugs are prescribed by physicians. The rate of first-time heroine use has reached a peak in the major cities in the USA in 1968. In smaller cities in 1980 it continues to rise. The exact number of people on heroine in the USA is unknown but according to [10] on drug abuse 2 million people in the United States have abused heroine. Those who have used Marihuana is around 43 million; hallucinogens 10 million and simulates 13 million.

\subsection{The undesirability of compulsive drug abuse}

There are a number of medical problems that are detrimental to the individual life or health and need to be suppressed e.g anxiety, fear, and sufferings. These can be relieved by using sedatives, hypnotics, anti anxiety and analgesics. On the other hand, their suppression it was though may decrease the adaptability of the individual and thus become undesirable. Drugs that produce physical dependence are powerful determinant of behavior. In order for the addict to satisfy his artificial appetite, life sustaining need are partially denied and social obligations are not met, with resulting harm to both the individual and the society [5]

\subsection{Social cost}

Non opiate abusers and addicts are seldom forced to steal or commit other crimes to pay for drugs, the social cost of non opiate abuse is less obvious than that of heroine abuse and receives less attention. The ultimate cost of non-opiate abuse to society is substantial when all its ramifications are considered. The cost associated with non opiate abuse can be measured in terms of productivity, industrial disruption, and unnecessary use of emergency rooms and psychiatric services. The treatment of physical dependence also expends considerable medical measures.

The dangers of drug and alcohol abuse are many. They are not confined to the toxic or the lethal effects on the individual. Drug and alcohol abusers often become un-productive, dissipating their available resources, neglecting their family and community obligations, becoming dangerous and threatening the safety of others while intoxicated as well as endangering their own lives because of drug and alcohol induced toxic effects. These dangers are magnified by the physical and psychological dependence produced by many drugs and by alcohol [1]. 


\section{The phenomenon of abuse}

Drug dependence is a complex phenomenon involving social, personal and pharmacological factors. It is at the same time a disease, a result of other diseases and a cause of criminal act. Fundamentally, it is an interaction of human being, their environment and a variety of drugs or chemical substances. The term drug abuse is difficult to define since it is based on social and cultural norms. In our culture the use of nicotine is not considered to be an abuse but it is considered to be a deviation from the dogmas of certain religious sect. Alcohol is a socially accepted drug usage in our society, yet certain degree and pattern of alcohol ingestion considered to be deviant or abnormal.

Drug abuse usually involves a persistent and excessive, non medical or non prescription use of chemical substances. Those drugs that are abused in our society are those that produce mind or mood altering effects. Drugs may be misused rather than abused if they are taken occasionally but in an indiscriminate or inappropriate way. The haphazard use of laxatives or antibiotics for example can constitute drug misuse by physician or lay-person [3].

\subsection{When does it start?}

Most drug addicts began experimenting with drugs when they are teens or early twenties. Data from Bureau of narcotics indicate that more than half the known addicts are less than 30 years of age. Most addicts have a history of delinquency and have experimented with other drugs such as tobacco, marihuana, alcohol, barbiturates and amphetamines before using narcotics.

\subsection{Hard and soft drug}

Non medical or non prescription use of drug can be classified into two (2) groups:

a. Hard Drug

b. Soft Drug

\subsubsection{Hard Drugs}

These are those drug that are liable seriously to cause disability to the individual as a functioning member of a society by inducing severe emotional and in case of cerebral depressants, physical dependence. Among these groups are heroin, morphine and analogue.

\subsubsection{Soft Drugs}

Soft drugs are less depending. They may produce emotional dependence but little or no physical dependence except with large doses of depressants e.g alcohol, barbiturates. The group includes sedatives, tranquilizers, amphetamines, cannabis, hallucinogen, alcohol and tobacco. Attempt to distinguish between the two terms fail because it does not seem to recognize individual variation in drug use. Barbiturate can be used in heavy, often in doses 
that are gravely disabling and induce severe physical dependence but upon withdrawal, it could result in serious convulsion. To such individual it is a hard drug. Some other people (middle aged) can use it as a mild hypnotics and sedative but still retain their position in the home and society. Amphetamines on the other hand can be regarded as hard or 'soft'. What is of assistance in distinguishing these two terms is that while 'hard' use is central to the individual life, the 'soft' use is mere individual. What is really or classified here is not the drug but the effect it produces or the way it is used by the individual. This also depends on the dose. As Paracelsus in the 16th century, once wrote, "The right dose differentiates a poison from a remedy".

Non-medical use of drug has two principal forms:

- Continuous use

- Intermittent or occasional use

Continuous use-Here there is a true dependence based on repeated usage. E.g Alcohol, Barbiturates, Opioids e.t.c.

Intermittent use-This is the occasional use of obtain an experience or relieve from stress; to obtain an experience, e.g (Lysergic acid Diethylamide) LSD, cannabis, amphetamine, cocaine, solvents or to relieve stress e.g alcohol. Some of the drugs can be used in both ways e.g alcohol while LSD; cannabis are confined to occasional use alone [7]

\section{Purpose for non-prescription use of drug}

- Relief from anxiety, stress, tension, depression or from personal psychological problems or detachment from harsh reality.

- Rebellion against orthodox social values and the environment.

- Fear of conforming with own social sub-group or of missing something.

- Search for self knowledge and for meaning in life and in religion, also in interpersonal relationship to have a sense of belonging.

\subsection{Culture}

Culture defined simply as the way of life. Here it was stated that drug provides spiritual, emotional and intellectual experience that are the basis of life. It is really not certain if chemical could be central to a constructive culture. It is another for a chemical to be destructive to one's way of life. Drug use is a secondary phenomenon and not primary issues when sub-group are for the individual and social value of experience must be tested on the basis of its fruitfulness to the individual and to the society. The judgment by the individual alone is not conclusive but attested to by majority of people. In fact, the result of illegal use of drug is not encouraging let alone its damaging effect [8] 
A good human quality is to love his neighbor in a practical and effective way. This cannot be promoted or diminished by drug. Obviously love of a neighbor is incompatible with driving a car over him. To believe drug e.g alcohol provide a vague benevolence is and of spirituality is doubted. What matters here is that it is not how a person feels but what he does in response to the feeling. The other claim by addict or abusers is that drug provides mystical experience; mystical experience has the following characteristics:

a. Unity-This is a sense of oneness with nature and with God too.

b. Joy, soundness, and peace.

c. That the experience is beyond human power to express or describe (i.e ineffability).

d. Transcendence of space and time.

e. An insight i.e. knowledge into the truth of life, values, illumination, revelations of enormous significance mystical experience is transient and passive. When drug provide this experience, I do not think the individual gain an insight into the truth of life or experience outside his own self.

Mysticism is of the following forms, Nature's mysticism, soul's mysticism and God's mysticism.

\subsection{What is mysticim?}

Mysticism has the following characteristics.

- Unity-It has a sense of oneness with God and/or nature.

- Ineffability-That the experience is beyond ones power to experience or describe.

- It provides joy, peace, soundness

- Knowledge-This is an insight into the truth of life illumination, revelation of enormous significance.

\subsection{Transcendence of space and time}

It shows that in mysticism the person's will is in abeyance, Transient and passive. When it occurs it tells us nothing about the real truth about the person's mind or reality outside the person's life or about the mind of the person having the experience.

At this juncture we will like to see the various forms of mysticism
a. Natures Mysticism
b. Soul's mysticism
c. God's mysticism 


\subsection{Nature's mysticism}

This is an institution as it appears so vivid to be a vision of reality in the world outside the mind. It is concerned with natural beauty and sublimity or a quasi personified nature as its object.

\subsection{Soul's mysticism}

The soul of the spirit strives to enter not into communion with God or nature but into isolation from everything other than itself. That is the quest for self and of knowledge about it.

\subsection{God's mysticism}

Here the spirit is absorbed into the God and there is complete union with God. There is also an inexpressible knowledge or love of God and religious youth. This type of experience is so attractive that the subject looks for easy way to deliver it. Apparently, they can be no mystical experience with drug. Mystical experience is not a normal dose-related pharmacodynamic effect of any drug. Its occurrence depends on the subject (mood, personality) and environment and any preparation he may have undergone. The drug can facilitate the experience but cannot induce it. For instance, drugs can facilitate pleasant or unpleasant experience. It is noted that drug can provide mystical experience if it alters consciousness. A good example of these drugs is chloroform. Quoting somebody's experience with this drug "I seem at first a state of utter blankness with a keen vision of what was going on in the room around me, but not sensation of touch. I thought that I was near death; who was manifestly dealing with me, handling me, so to speak in an intense personal, present reality... I cannot describe the ecstasy I felt". In this place we can see that there is no good evidence that drug can produce experience that passes the test of result i.e fruitfulness.

Reliance on repeated drug experience as in drug abuse or non-medical use of drug even inhibits the subject's complete isolation from the material things of this world which is to be described as freedom of spirit [8]. Whether a single administration of drug can trigger or initiate experience which is beneficial to the individual is still to be proven. For instance, if emotional shock is acceptable in religious conversation, there seems so obvious reason why a drug should not also be used after careful preparation. There is always risk of the experience becoming an end rather than a means of development. It has been found out that psilocybin (a hallucinogen) facilitates mystical experience. It has to be noted again that a religious man is not a man with experience but takes the whole life in a religious way.

\section{Tissue toxicity}

All drugs that produce dependency in individual are liable to cause tissue toxicity with excessive use. It is not surprising to see users of narcotic to die of respiratory depression. Barbiturates and alcohol produce the same effect. Opiates produce chronic toxicity while alcohol produces many, mainly liver damage [7] 


\subsection{Mechanisms of overdose and toxicity in opioids}

There has been an increasing recognition of the problems of fatal opioids overdose. The pharmacological basis of respiratory depression following opioids administration will be stated here. Respiration is controlled principally through medullary respiratory centres with peripheral input from chemoreceptors and other sources. Opioids, produce inhibition at the chemoreceptors via mu $(\mu)$ opioids receptors and in the medulla via mu $(\mu)$ and delta $(\delta)$ receptors. While there are a number of neurotransmitters mediating the control of respiration, glutamate and GABA are the major excitatory and inhibitory neurotransmitters respectively. This explains the potential for interaction of opioids with benzodiazepines and alcohol: both benzodiazepines and alcohol facilitates the inhibitory effects of GABA at the GABA receptors, while alcohol also decreases the excitation of glutamate at NMDA receptors. Heroin and methadone are the major opioids implicated in fatal overdose. Heroine has three metabolites with opioids activity. Variation in the formation of these metabolites due to genetic factors and the use of other drugs could explain differential sensitivity to overdose. Metabolites of methadone contribute little to its action. However, variation in the rate of metabolism due to genetic factors and other drugs used can modify methadone concentration and hence overdose risk. The degree of tolerance also determines risks. Tolerance to respiratory depression is less than complete, and may be slower than tolerance to euphoric and other effects. One consequence of this may be a relatively high risk of overdose among experienced opiods users. While agonist administration modifies receptor function, changes (usually in the opposite direction) also result from use of antagonists. The potential for supersensivity to opioids following a period of administration of antagonists such as naltrexone warrants further investigation [9]

\section{Social effect}

We are all aware of the social and moral havoc produced by narcotic addict in order to obtain their drugs. Drugs have been linked to criminality because of the dubious means employed to get them compulsorily and not necessarily that drug induced the criminal act. Other social aspect of drug dependence is the inability of the addict to be productive or economic independence as well as member of his or her family. There is always a breakdown of interpersonal relationship and emotional support because the individual is busy or is not concerned with his drug and so isolate himself. He then avoids both personal and social obligations [5]

\section{Factors determining the abuse potentiality of a drug}

Some of these factors have the capacity to induce compulsory drug-seeking behavior, its toxicity and social attitudes towards drug effects and use. Since antiquity, drugs that produce dependency problem have been known. It is not clear when their dependency producing nature was first recognized. Opium preparations were used as soporific agents, analgesics anti-diarrheic antipyretics in ancient civilizations. These drugs were used to an extent even in 
those times that some of them were physically dependent on them.In the middle of $19^{\text {th }}$ century, opiate abuse was first recognized on a world wide scale especially in China. It became a problem because of the introduction of opium smoking and the commercial exploitation of opium grown in India and sold by the East Indian Company. At this point the consumption of morphine and opium was increasing in the United State. The ready availability of these products the supply by the Chinese labourers and the use of morphine as a pure salt for hypodermic injection makes the addiction a problem [10]

In 1909, the effective narcotic law was passed which prohibit the trafficking of opium and morphine (narcotics) except on medical ground. This prohibits the sale not only in U.S.A but also by the USA Commission on trafficking in narcotics to suppress the sale and consumption of narcotics in the far east. Because of the high profit from the illegal sale of narcotics, effort to arrest this act is still not successful.

\section{Approaches to the drug abuse problems}

There are varieties of approach to the incidence of drug abuse. The first is to prevent its occurrence by introducing a course on drug and drug abuse in the elementary, secondary and tertiary institution. The success of this needs further research. Other ways to prevent the abuse of drug is to alleviate the social and economic factor that is associated with drug abuse. Advice should be given to individuals on how to cope with anxiety and other stressful condition.

The legal approach could be by making the drug illegal and presumably unavailable. This approach is so primitive than other approaches. By making it illegal will drive the drug to the black market and high prices will be attached to them. In this case the individual will seek a more expensive and more criminal method in having the drug by all means to satisfy his urge or satisfaction. Other way is to introduce an alternative to the abuse drug e.g the use of nicotine gum in cigarette smokes so that others do not partake in sharing some percentages of nicotine while it's been smoked publicly. Rehabilitating the subject could be of advantage e.g "let them know about the cause of drug dependence, they could be also rehabilitated by complete withdrawal from the drug, or a modified drug use, vocational training, improvement of self image and development of changes in life style and attitude" [10]

\section{Legalization of drug abuse or non-medical use of drug}

A drug can be acceptable in medical practice if it is safe and its efficacy is guaranteed. These same principles should be used for non-medical use of drug. But the usual critical factor for judging efficacy against a disease or discomfort should not or hardly apply here. Some reasons why people abuse drug or non-medical use have been highlighted but not one carry weight if the drug is found to be a health-risk. These are some of the reasons why people abuse cannabis, for example. Medical prudence dictates that such risk be defined before legalization is to be effected. Indirectly, drug abuse can result in loss of education or employment. If laws are 
implemented autocratically, it can lead to corruption among people, police and even alienation of important persons from the society who could have been part of decision making. Lack of discrimination by the law may lead to progression by the association from less to a more harmful drug since similar illegal behavior is needed to obtain all. But though written laws are so often inflexible and grouped together what would best be separated. Informal judicial discretion under the present law may be permitting more experimentation than would recurrent. Legislative debate leading to substitution of one written law for another written law may be encouraged. This untidy approach which may be best for the time being cannot certify the extravagant advocate either of reliance or of repression. What normally happens is that penalty for possession of small amount be removed (which is discrimination) whilst retaining penalties for suppliers [11]

\section{Drug abuse and sport}

In competitive sport, the goal for self or personal, national, financial prestiges are the cause of determination to win at all cost. Most of the drugs abused are those that enhance performance e.g anabolic steroids. The efficacy of this is largely not documented.

Drugs are abused in sports for the following reasons:

a. For events in which body weight, brute, strength are the principal determinants (e.g weigh lifters, shot put, rowing etc). A good example here is anabolic steroids. Whether this has effect on performance is doubted apart from increasing the lean body weight.

b. For event in which output of energy is explosive. The stimulants are used e.g Fencamfamin. These are used in bicycling, marathon racing e.t.c

c. For events in which steadiness is essential e.g pistol, rifle shooting e.t.c subjects may use adrenoreptor blockers.

d. For events in which body phancy is essential e.g in gymnastics, delaying puberty in child gymnasts by endocrine techniques.

In case of minor injuries in athletes, the use of non steroidal anti inflammatory drug is rampant and also corticosteroids so that training will proceed maximally. In some cases females have been virilised to outperform their sisters by the administration of androgen. These are administered for immediate gain of fame [8]

\section{Drugs abuse liability}

Drug most likely to be misused if not compulsively abused are those that can alter mood or behavior in ways that satisfy the emotional needs of certain individual. The classes of therapeutic central nervous system agents that are known to be misused for non therapeutic purposes include the sedative - hypnotics, alcohol, narcotic, analgesics, antagonists, sympa- 
thomimetic stimulants such as metamphitamine, and certain general anesthetics such as ether and nitrous oxide. Other misused compound that have notable central nervous system effect but without proven therapeutic usefulness includes marihuana and lysergic acid diethylamide (LSD). The first gratifying drug experience is frequently, but certainly not necessarily [3]

\section{Drug dependence}

Drug dependence may be defined as a state resulting from an interaction of a person and a drug in which there is a compulsion to continue taking the drug to experience a pleasurable psychological effect and sometimes avoid discomfort due to its withdrawal. There are several groups of drug of dependence: Opioids, cocaine, Amphetamine, and Ecstasy, Barbiturates, Nicotine, Alcohol, Hallucinogens, Caffeine e.t.c. Drug dependence may also be defined as a state which arises from a repeated, periodic or continuous use or administration of drug. This could result in harm to the individual and sometimes to the society. The individual feels a desire or a need or compulsion to continue taking the drug. This is referred to as withdrawal or abstinence syndromes. The term drug dependence according to the World Health Organization (WHO) could be substituted for addiction and habit [12]

Dependence is characterized by the following phenomenon:

a. Emotional or psychic dependence

b. Physical dependence

c. Tolerance

\subsection{Emotional dependence}

This is the first to occur if the drug is discontinued. The person become emotional or may be in distress.

\subsection{Physical dependence}

There is physical illness if the subject discontinues the drug called withdrawal syndrome. In physical dependence, repeated administration produces biochemical changes in the subject taking the drug. If the drug is withdrawn, very unpleasant symptoms and signs of physical nature develops which may last for a varying period, but will finally disappear. During this period, there is intense craving for the drug, which, if given, will temporarily relieve the unpleasant symptoms. Thus, after the establishment of physical dependence, the patient's drug-seeking behavior is motivated chiefly by fear of the withdrawal symptoms [12]

\subsection{Tolerance}

Tolerance is a phenomenon whereby more of the drug is needed to produce the same response. This often develops with drugs causing dependence, especially morphine and heroin. 
Tolerance usually (but not always) develops to the central but not peripheral effects of a drug. Morphine and heroin causes euphoria (central) and constipation (peripheral). Thus, with heroin or morphine, tolerance to the central effects develops invariably, and the user will have to keep increasing the dose to get the euphoria, but will not develop tolerance to the drugs effect in causing constipation and will be severely and chronically constipated. This even occurs with many drugs that do not induce dependence e.g Lysergic acid diethylamide (LSD). This results from compensatory biochemical cell response to continued exposure to the drug e.g opioid. Both physical dependence and tolerance could result from homoestatic of adaptation to continued occupancy of the receptors e.g opioids. It could also occur with Gamma amino Butyric Acid (GABA) receptors [12]

Physical dependence develops to a substantial degree with cerebral antidepressants but less with stimulants e.g amphetamines. There is usually cross tolerance between drugs of similar or dissimilar chemical group e.g Barbiturates, Benzodiazepine, alcohol. No drug possesses any mysterious powers to subjugate any person. It is said that "the first exposure to any drug could be an index of addictive proneness".

Emotional dependence occur to any drug that alter consciousness however bizarre e.g muscarine. To some in ordinary doses do not e.g non narcotic analgesics, diuretics or purgatives. Dependence also depends on the patient belief about the drug. For instance those depending on purgative and diuretics are obsessed with the dread of obesity. Emotional dependence can occur by taking either tablet or injection and it also depend on the content. We are all physically dependent on food but some with a stronger emotional dependence eats too much [5]

\subsection{Psychological dependence}

In psychological dependence, the patient exhibits a compulsive drug-seeking behavior. The drug often produces a pleasant feeling, often relaxation, freedom from worry, or heightened awareness and increased energy and sexual drive. The patients suffer mental anguish when it is withdrawn.It was customary to divide regular continuous drug abuse to two categories: Addiction, Habit $[7,12]$

\section{Addiction, habit}

Addiction here shows that there is a compulsion to continue taking the drug whereas in habit is a mere desire to continue taking the drug. In addition, the harmful effect is to the individual and the society at large while in habit the harm is to the individual alone. This difference cannot be quantified in the sense that what is considered to be addiction in one subject could be a mere habit in another. In some other cases in addiction, the individual could have both emotional and physical dependence. In habit the subject is confined to only emotional dependence.

Even with these differences, there is still fault. For instance alcohol is a drug of addiction to many in which the individual becomes physically dependent on it and without it could become 
ill. In some other people, it is a case of just solace or just pleasure and some take it on a regular basis. Of course, these may be the reason why the term 'addiction' and 'habit' are replaced by dependence. This term removes irrelevant argument or difference between the two terms which are never true differences and also remove the arguments that tobacco is addictive or habit-forming.

Dependence on a drug depends on some factors among which are the availability of the drug itself, the subject personality disorders and the socio-economic factor. The speed of onset of dependence and its tendency to induce emotional, physical dependence depends on the pharmacological actions of the drugs, dose and the frequency with which it is administered $[1,12]$

\subsection{Reasons for drug abuse and tolerance}

Drugs may be used intermittently for social or emotional reasons - for example, to relieve a stressful situation. Those who are truly dependent take drugs continually and may reach a state in which their whole life centres on obtaining and using drugs. Dependence may not be confined to one drug or groups of drugs. It is common to find dependent subjects who have escalated from minor drugs (for example, Canabis) to hard drugs (for example, Heroin) and some subjects may alternate or combine drugs; for example, Cocaine and morphine would produce alternating stimulation and relaxation. It is a difficult question to know why people depend on drugs. The answer is still incomplete. People may depend on drugs for the following reasons; curiosity and wanting to belong, chemical props and escapism, biological make-up, availability, pressure at work [12]

\section{The mechanism of physical dependence}

This could be related to tolerance but is poorly understood. The physical dependence and tolerance implies that the adaptive changes have taken place in the body tissues and that changes are lost and in consequence, there is rebound over activity. It was discovered that there is morphine-like substances called endorphins and that the CNS employs this as a neurotransmitter. This allows speculation that exogenous administration of morphine could suppress endorphins and that when the drug is withdrawn, the lowered endorphin cannot immediately compensate this because the suppression was due to a feedback mechanism. Because of this immediate deficiency, there is a withdrawal syndrome [8]

\section{Pattern of drug abuse or non-medical use of drug}

Any age: Alcoholism - mild dependence on hypnotics and tranquilizers: Occasional use of LSD and cannabis. 
20 - 35 years of Age: Hard use drugs e.g heroine, morphine (imported illicitly) and synthetic analogue - dipipanone, methadone (diverted prescription) or amphetamine injected.

Under 16 years: Volatile inhalants: solvent of glue, aerosol sprays, glue sniffing, paints, inhalation of excreta from toilets e.t.c [8]

\section{Multiple drug abuse}

These are the following; Hypnotics, sedatives, amphetamines, cocaine, opioids e.t.c. The pattern of use of these drugs changes frequently [7]

\section{Drug supply to addicts}

In the UK the supply of drugs to addicts especially heroine and opioid is by specially licensed doctors. The subjects are either on treatment or fail to respond to treatment. This is done to maintain the patient as total withdrawal can lead to withdrawal syndrome. To avoid infection, sterilized syringes and the pure drug could be supplied and this pure drug may discourage them from taking the drug which may be adulterated. Oral methadone is convenient and may occupy the opioid receptor which reduces the kick produced by the injectable opioids. This procedure is very good to some extent because as the price of these drugs fluctuates (high), the subject uses more illicit way to obtaining the drug and can result to crime. Prescription of this drug ensures a measured drug is provided for the patient and not him requesting for an xmg of drug. He or she can sell it to others as well as initiating other people [5]

\section{Withdrawal syndrome in opioids dependence or addiction}

No doubt, withdrawal can cause unpleasant feelings in addict. To say addicts continuously seek the drug primarily to avoid the unpleasantness is false. There is the capacity to relapse after complete withdrawal and it has been recorded. Addicts seek super normally rather than normally to get their drugs and also seek intense pleasurable 'kick' or 'high' so that after complete withdrawal, the psychopathic or neurotic addict still have tendency to revert to drug [8]

\section{Treatment of severe pain}

This may present special problem when high efficacy opioid is used, they may either be tolerance or toxicity could result. When low efficacy opioid is used, not only will it be ineffective but there could be withdrawal syndrome especially if they are agonist/antagonist e.g 
pentazocine. This leaves aspirin as a drug of choice. Aspirin could be given in combination to ensure efficacy. For instance, Aspirin 600mg and aminoacetic acid 300mg. Nefopam is a nonopioid analgesics which could be used to relieve pain [8]

\section{Route of administration of drug}

Highest plasma concentration occurs with intravenous route as compared to oral route. This is responsible for the 'kick' of 'flash' reported by addict. Addict who seeks illegal means of drug use could be supplied with diluted drug which if supplied with pure drug could result in toxicity [12]

\section{Mortality}

Especially young people that abuse and are addicted to heroin, barbiturates, amphetamines by intravenous route die of septicemias, Acquired immune Deficiency Syndrome (AIDS), tetanus gas gangrene, endocarditis, pulmonary embolus e.t.c [10]

\section{Escalation}

There is possibility that subjects progress from soft to hard drugs. For instance, individual on cannabis and amphetamine could progress to a harder one i.e heroin and even be addicted to it. This brings the idea of cross tolerance [1]

\subsection{De-escalation}

As the subject progress or advances in age, he or she is disillusioned with taking these drugs. Any drug that alters ones consciousness is liable to be abused, even with anti-parkinsonism e.g levodopa, anticholinergics [8]

\section{Substance abuse}

A number of substances are abused. This is attributed to seekers of self gratifying 'high' who often inhale volatile substances that affect the central nervous system. Substances like glue sniffing, aerosol, petrol, paint scraping, nail-vanish, lacquer paint solvents (snuffing), butane gas which later with continuous use can paralyze the larynx and in consequence, food materials, gastric contents, drinks could enter the respiratory tract and could even flood the lungs and eventually death will occur. Some of these aerosols could be sprayed in a plastic bag or in confined enclosure and the subject will begin to inhale. This has serious consequences 
which ultimately lead to death. Some drugs are deliberately designed to suite chemist needs which could be of high efficacy. This is by molecular modification by skillful and criminally minded chemists.

Pethidine production could be by short cut leading to a substance closely related to a byproduct. Example is melthylphenyltetrapyridine (MPTP). This is known to have parkisonian syndrome which may respond to levodopa. MPTP selectively destroys the melanin containing cells in the substantia nigra [8]

\section{Treatment of drug dependence}

A step toward social and psychological rehabilitation is to withdraw the drug. This is a long and often disappointing journey to psychological and social rehabilitation. In the case of physical dependence, the drug is withdrawn gradually over a long period of time. It may be done for about 10 days and steps should be taken to control abstinence syndrome. In some of the chemicals, a different chemical should be substituted. E.g for heroin, methadone can be given. For alcohol, it is better to use diazepam, chlormethiazole or chlordiazepoxide could be used. A barbiturate is substituted with $30 \mathrm{mg}$ phenobarbitone up to a maximum of $400 \mathrm{mg}$ phenobarbitone per day for every $100 \mathrm{mg}$ barbiturates. Some patients are in a very poor physical state. In such a case effort should be made to wait for sometimes until the patient is a little normal.

In some cases of sympathetic autonomic over activity, B-adrenoceptor blocking drugs should be used e.g clonidine.

Maintenance should be by supervision by medical personnel where there is hope of cure. In this case the addict should be supplied with the same or alternative drugs but by less harmful routes e.g patient who prefers to use intravenous (I.V) route for heroine should be given oral methadone. It is so because the patient preffer to be excited as quickly as possible and that the I.V produce the immediate high.

Measurement of blood or urine level of some of the drug is important for effective management of drug abuse. Testing of some of the drug to know their power as to induce abstinence syndrome should be done. This is by giving animals' e.g monkeys. Some percentage of the drug regularly and abruptly is withdrawn to see the withdrawal syndrome. The power of a drug to control abstinence syndrome could be another serious problem because it could cause serious dependence.

The World Health Organization (WHO) recommends drug dependence should be classified by types.

\section{Tobacco Type:}

- Emotional dependence is high

- Physical dependence is slight 


\section{Alcohol Type}

- Emotional dependence is severe

- Physical dependence with prolong use

- Cross tolerance with similar sedatives

\section{Cocaine Type}

- Psychic dependence is severe

- Physical dependence is slight or absent

- Tolerance is absent.

\section{Canabis Type}

- Emotional dependence in some

- Physical dependence is slight or dubious.

- There is no characteristics abstinence syndrome.

- Tolerance is slight.

\section{Amphetamine}

- Emotional dependence is severe

- Physical dependence is slight

- Tolerance exists

- Psychoses occur during use

\section{Barbiturates Type}

- Psychic dependence is severe

- Physical dependence is severe. It develops slowly with continuous use.

- Cross tolerance occur with alcohol, diazepam, chlordiazepoxide, meprobamate, glutethimide, chloral, paraldadyde

\section{Morphine Types}

- Emotional dependence is severe

- Physical dependence is severe, develops rapidly.

- Tolerance occur with related drugs

- Naloxone induce abstinence syndrome.

\section{Drug Mixtures}

In this case there is alteration of mood. 
- Psychic dependence is severe

- Physical dependence is strong

- Tolerance exists

\section{Heroin, Cocaine}

These combinations have similar characteristics [8]

\section{Prevention of drug dependence after medical use of drug}

If drugs are used or handled properly, there is no need of drug addiction but when drugs are used excessively especially analgesics, and then dependence will occur. Prevention could be brought about by spacing the drug dosages as much as Possible. Effort should also be made by withdrawing the drug of addiction from the patients or conceal the nature of the drug. In some patient whose expectation of life is little, there is no need to bother much on drug dependence when planning therapy

\section{Tobacco}

Tobacco was introduced to Europe from South America in the $16^{\text {th }}$ century. Tobacco is habit forming. In the USA, the Federal Government spends her subsidies to tobacco farmer's larger sums than it does on telling people not to smoke. The highest production of tobacco is from USA, India, USSR and china

\subsection{Composition of tobacco smoke}

There are about 500 compounds in tobacco smoke. The chief pharmacologically active substance is nicotine-acute effect and rare-chronic effect. The smoke of cigars and pipes is alkaline (PH 8.5) and nicotine is un-ionized and lipid soluble and is absorbed in the mouth. Smokers of cigars and pipe have lower death rate from lung cancer because they do not need to inhale to obtain nicotine as it is alkaline and lipid soluble. Smoke of cigarettes is acidic and the nicotine is lipid insoluble and ionized. In this case the smoker needs to inhale to obtain and coupled with large surface area for absorption in the lung will absorb a substantial quantity of nicotine and the individual will suffer lung cancer. The amount of nicotine by smokers is about $90 \%$ and in non-smokers by about $10 \%$. The tobacco contains about $1-5 \%$ carbon monoxide. In habitual smokers it's about $3-7 \%$. In heavy smokers, about $15 \%$ of their blood is carboxy-haemoglobin. This cannot carry oxygen. This is enough to induce angina pectoris.

Chronic carboxy-haemoglobinaemia causes polycythaemia. Tobacco is known to contain polycyclic hydrocarbon and N-nitroso compound. These compounds are carcinogenic and are responsible for the microsomal enzyme inducers in smokers [8] 


\subsection{Tobacco dependence}

The reason why people smoke is a complex phenomenon. The purported benefits on mental health are so intangible and elusive, so intricately woven into the whole fabric of human behavior, so subject to moral interpretation and censure, so difficult of medical evaluation and so controversial in nature that few scientific groups have attempted to study the subject.

Satisfaction of smoking is due to nicotine and also tars which provide the flavour. There is no clear cut personality difference between smokers and non-smokers. Cigarette smokers tend to be more extraverted, less rigid and more prone to antisocial behavior than non smokers. Cigars and pipes smokers are introverted.

Again, smoking is not associated with neurotism or is they liable to psychiatric problem. To this problem, psychoanalysts have made characteristics contribution to this. "Getting something orally" one asserts "is the great libidinous experience in life"; first, the breast, then the bottle, then the comforter, food and finally, the cigarette. Those who give up smoking substitute it with other oral activities e.g nail biting, gum chewing and eating.

Sigmud Freud was a life-long tobacco addict. He suggested that some children may be victims of a "constitutional intensification of the erotogenic significance of the labial region" which if it persist will provide a powerful motive for smoking. Beginning to smoke is related to status need, personality recognition, and self esteem and is not due to rebellion. "That which hath made them drunk hath made me bold" [13]. There is no difference in intelligence between smokers and non smokers but non-smokers are more academically favoured or successful then smokers. Learning to smoke occurs in adolescent and mostly in the age of 20 years. The factor that facilitates smoking initially is psychosocial with pharmacodynamic factor unpleasant. With the psyco-social pressures especially from members of the same age group, one get used to the benefits of nicotine, learning to avoid and coping with the various pharmacodynamic unpleasantness. As he progresses, the psychosocial factors diminish and are replaced with the desire and need for nicotine. The subject with the fear of withdrawal syndrome and maintenance of nicotine level in the blood, he then develops high drive for nicotine consumption and tendency to be a chain smoker. People who want to smoke in order to become 'tough' or grown up, outgrown this immature drive and smoke because of the pleasure they derive from the nicotine. Offering and accepting to smoke is another factor. There is also development of personal relations in business and private life. People do smoke because, to them it relief them of the stressful situation and it may be that smoking is an expression of stress [8]

\subsection{Types of smoking}

Smoking could be pharmacological or non-pharmacological.

\subsubsection{Non-pharmacological}

This includes:

i. Psychosocial: This is done to increase self esteem, status need, personality.

ii. Sensorimotor: To achieve oral, sensory or manipulative satisfaction. 


\subsubsection{Pharmacological}

By Changes in puffing and inhalation rate, the plasma concentration of nicotine is adjusted automatically.

Indulgent: To obtain pleasure or to enhance already pleasurable condition.

Sedative: to ease unpleasant conduction.

Stimulant: Help performance of monotonous task, to escape stressful condition or to get a 'life' in order to perform.

Another case is where the subject smokes automatically, being unaware of the act. He becomes aware of the act only when the cigarette is not at hand [5]

\subsection{Acute effect of smoking tobacco}

Airway resistance: Accumulation of carbon particles can result in bronchial narrowing sufficient to double airway resistance. This is insufficient to cause dyspnoea but four to five fold increase cause noticeable dyspnoea and in about 20 fold can cause severe dysponea as occur in asthma. Nicotine does not increase airway resistance.

Colliery Activity: Develops after the drug is gradually withdrawn or after transient stimulation in depressed.

Carbon monoxide Absorption: Is less in healthy young adult but become significant in coronary heart disease.

Nicotine is well absorbed with a plasma half-life $\left(t^{1} / 2\right)$ of 2 hours. Nicotine can stimulate or depress nervous tissue depending on doses and dosage interval and the psychological state of the patient. It cans relief boredom or stressful situation. Smokers who become more alert tend to take a lower dose of nicotine than smokers who become tranquil. Nicotine causes the release of catecholamines from the hypothalamus and anti-diuretic hormones from the posterior pituitary. In large doses it stimulates the end of peripheral cholinergic nerve whose cell bodies lie in the central nervous system. It acts at autonomic ganglia and neuromuscular junction. This is called the nicotine-like or nicotine effect. Higher doses paralyse the same point. The central nervous system is stimulated with the vomiting centre. Tremors, convulsion could result. Depression follows stimulation in case of peripheral actions. The nicotinic effect can be blocked by the canuylamine which antagonize the nicotinic acetylcholine receptors.

"Fatal nicotine poisoning has been reported from smoking, from swallowing tobacco, from tobacco traumas, from topical application to the skin and from accidental drinking of nicotine insecticide preparation. In 1992 a florist sat down on a chair, on the minutes later he felt ill (vomiting, sweating, faintness and respiration difficulty, following by lose of consciousness and cardiac irregularity). He recovered in hospital over 24 hours. On the $4^{\text {th }}$ day he was deemed well enough to leave hospital and was given his clothes which damp. Within one hour of leaving hospital he had to be readmitted suffering once again from nicotine poisoning. $\mathrm{He}$ recovered over three weeks, but for persistent ventricular extra systole" [8] 


\section{Conclusion}

Conclusively, the above brief discussions do little more than raise issues that deserve considerations. Drug induced experience can only be discussed in terms of attitudes and beliefs held by the individual as to the nature of man, his purpose (if any), his obligations (if any) and his relationship to a transcendent being or God (if any) and there is no good evidence that drugs can produce experience that passes the test of result, e.g fruitfulness. Indeed, reliance on repeated drug experience may even inhibit the development of independence from the material things of this world, which is vital for anything that deserves to be described as freedom of spirit.

Whether a single administration of a drug can be used to initiate or trigger experience that may result in an individual gaining beneficial insight is unproved. Finally, there is a risk of the experience becoming an end in itself rather than a means of development.

\section{Acknowledgements}

We will like to give thanks to almighty God for making it possible to bring this piece of information and research to the audience. Our regards to the typist who out of his tight schedule, was able to help in typing some parts of this manuscript. Our regard to Professor J. A. Anuka, who, assisted in proofreading a part of this manuscript. For as many that contributed to the success of this work, many thanks to all of you.

\section{Author details}

Alewu Benjamin ${ }^{1}$ and Nosiri Chidi ${ }^{2}$

1 Department of General and Applied Sciences, Makarfi, Kaduna State, Nigeria

2 Shehu Idris College of Health Sciences and Technology, Makarfi, Kaduna State, Nigeria

\section{References}

[1] Sollman T. (1957), Manual of Pharmacology. (Ed. 8.) Philadelphia, Saunders.

[2] World Health Organization (WHO), (1957). The expert committee on addiction-producing drugs of the WHO. Geneva. PP 76 
[3] Sutherland V.C., (1970). A synopsis of Pharmacology, Ed. 2 Eddy, N. B. Halbach, H. Isbell, H., Seevers, M. H. (1965). Drug dependence: Its significance and characteristics. Bulletin of World Health Organisation, 23: PP 721-722

[4] Donald, R. Wesson et al. (1978). Poly-drug, the result of national collaborative study. Editorial. British Medical Journal, (2): pp 1465

[5] National Commission on Marijuana and Drug Abuse, (1957). Report: Drug use in America: problem in perspective. Washington D. C. Government Printing Office.

[6] TinkTen-Berg and Berger, (1977) Poly-Drug Abuse.

[7] Laurence, D. R. \& Bennet, P. N. (1987). Clinical Pharmacology (Ed. 6.) PP. 387 - 392

[8] White, J. M \& Invine, R. J. (1999). Mechanism of fatal opiods overdose. Addiction, 94(7): PP 961-72

[9] Shin, (1980). In drug-induced sufferings. Proceedings of the Kyoto International Conference against Drug-induce Suffering 14 - 18 April, 1979, Kyoto International conference Hall, Kyoto, Japan Ed. T. Soda P. 141

[10] Cohen, J. (1963). Alcohol and road traffic. London: British Medical Association.

[11] Ben, G., Dina, G. (2009). Trounce's clinical pharmacology for nurses. (Ed. 8.) Churchil Living Stone. Elsvier. Edinburgh. London. PP. 290-1

[12] Shakespare, W. That which hath made them drunk hath made me bold. Lady Macbeth in Macbeth acts 2 Scene 2.

[13] Zinberg, N. E. (1984). Drug, set and settings: The basis of controlled intoxicant use. Oxford University Press. ISBN 0-300-03110-6. P 38 